\title{
As conferências ambientais da ONU e o prêmio Nobel da Paz: ganhos intangíveis em declínio?
}

\section{The UN environment conferences and the Nobel Peace prize: intangible gains in decline?}

Jefferson Wagner e Silva Galvão - Doutorando em Relações Internacionais pela Universidade de Brasília (UnB). Ouvidor Geral da Universidade Federal do Pará (UFPA). E-mail: jef@ ufpa.br

Carlos Eduardo de Souza Siqueira - Doutorando em Relações Internacionais Internacionais pela Universidade de Brasília (UnB). Professor da Faculdade Integrada Brasil Amazônia (FIBRA). Coordenador da ONG Argonautas Ambientalistas da Amazônia. E-mail: edu13siqueira@gmail.com

Ana Flávia Barros-Platiau - Doutora em Relações Internacionais/Direito Internacional pela Université de Paris I (Panthéon-Sorbonne). Professora da Universidade de Brasília no Instituto de Relações Internacionais. Coordenadora da Pós-Graduação. Fez pós-doutorado no CERIC (Centre d'Etudes et de Recherches Internationales et Communautaires) da Universidade Aix Marseille (França). E-mail: anaflaviaplatiau@gmail.com

\section{Resumo}

O objetivo do estudo é descortinar as possibilidades de ganhos intangíveis decorrentes das Conferências Ambientais da ONU. O Prêmio Nobel da Paz de 2017, atribuído a uma ONG que militou pela proibição total das armas nucleares demonstra o quanto as sociedades se organizam pela paz. Em 2007, Al Gore Jr. e o IPCC (Painel Intergovernamental para Mudanças Climáticas) já haviam dividido esse prêmio por seus esforços para desenvolver e disseminar maior conhecimento sobre mudanças climáticas. Entretanto, a Rio+20 foi considerada como um fracasso anunciado. Mas, não haveria ganhos intangíveis a considerar após décadas de debates sob a égide da ONU para a construção de consenso sobre a governança global ambiental? Foi realizada uma avaliação qualitativa dessas conferências e de artigos científicos. Os resultados apontam ganhos intangíveis dentro e fora do sistema onusiano. Concluímos que essas conferências geram ganho social global a partir da participação que proporcionam. Neste sentido, as conferências foram muito exitosas.

\section{Palavras-chave}

Clima. Rio+20. Ganhos Tangíveis e Intangíveis. Espaço Público Institucional.

\begin{abstract}
The objective of the study is to uncover the possibilities of intangible gains arising from the UN Environmental Conferences. The 2017 Nobel Peace Prize, attributed to an NGO that fought for the total ban on nuclear weapons, demonstrates how societies organize for peace. In 2007, Al Gore Jr. and the IPCC had already shared this award for their efforts to disseminate greater awareness about climate change. However, Rio +20 was considered a predictable failure. But would there be no intangible gains after decades of UN-led discussions to build consensus on global environmental governance? A qualitative evaluation of these conferences based on scientific articles led to the results that there were significant intangible gains within and outside the UN system. We conclude that these conferences engender global social gains from the participation they foster. In this sense, the conferences were very successful.
\end{abstract}

\section{Keywords}

Climate. Rio + 20. Tangible and Intangible Gains. Institutional Public Space. 


\section{INTRODUÇÃO}

Em 2007, o ex-vice-presidente dos Estados Unidos e ativista ambiental Albert Arnold (Al) Gore Jr. e o Painel Intergovernamental para Mudanças Climáticas (IPCC) compartilharam o prêmio Nobel da Paz por seus esforços para promover o regime global do clima. Dez anos depois, o Prêmio Nobel da Paz foi atribuído à International Campaign to Abolish Nuclear Weapons (ICAN). A ICAN é uma coalizão de centenas de ONG com sede em Genebra, que trabalhou ativamente com alguns Estados para a assinatura do Tratado para Proibição de Armas Nucleares (ONU, 2017), aberto para assinatura durante a Assembleia Geral da ONU em 2017. O primeiro a assinar foi o presidente brasileiro, e o tratado recebeu quatro ratificações no seu primeiro dia.

As indicações para o prêmio Nobel da Paz são feitas ao Comitê Nobel norueguês por nominadores ${ }^{1}$ de todo o mundo, o que garante uma grande variedade de candidatos. Qualquer pessoa ou organização pode ser nomeada por qualquer pessoa elegível para nomear. A nomeação é feita a partir de um processo de triagem e tomada de decisões de oito meses que envolve não apenas o Comitê Nobel norueguês de cinco membros - responsável final pela escolha - e seu secretário, mas também um grupo de consultores noruegueses e internacionais. O Comitê elabora uma lista restrita a partir da lista ampla elaborada com os indicados pelos nominadores. Os consultores, selecionados com base em sua experiência profissional e experiência acadêmica, preparam relatórios individuais sobre os candidatos dessa lista restrita que servirão, juntamente com outras informações relevantes, de subsídio para as deliberações dos membros do Comitê. Esse processo se repete com relatórios adicionais até restringirem o número de candidatos a um grupo muito pequeno. Por fim, o Comitê toma sua decisão por maioria simples.

O prêmio corresponde, em larga medida, à expectativa da opinião pública mundial de viver em paz, com segurança e num Planeta melhor, conforme os objetivos previstos na Carta da ONU em 1945. Estes dois fatos não são anódinos, haja vista que decorrem de iniciativas privadas conjugadas com políticas públicas para o fortalecimento da governança global do desenvolvimento sustentável, produzindo interações complexas com o sistema ONU.

\footnotetext{
1 Reitores ou chanceleres universitários, professores de ciências políticas e sociais, história, filosofia, direito e teologia; líderes de institutos de pesquisa da paz e institutos de relações exteriores; membros de assembleias nacionais, governos e tribunais internacionais de direito; ganhadores do Prêmio Nobel da Paz anteriores; membros do conselho de organizações e instituições que receberam o Prêmio Nobel da Paz; membros atuais e passados do Comitê Norueguês do Nobel; e ex-assessores do Instituto Nobel Norueguês (NOBEL FOUNDATION).
} 
Desde 1972, a agenda ambiental tem sido ampliada dentro e fora dos Estados e do sistema ONU, para a construção na década seguinte do conceito estruturante de desenvolvimento sustentável, que alude “às necessidades do presente sem comprometer a possibilidade de as gerações futuras atenderem a suas próprias necessidades" (COMISSÃO MUNDIAL SOBRE MEIO AMBIENTE E DESENVOLVIMENTO, 1991, p. 46). Alguns processos que levaram a este contexto são a internacionalização dos desafios globais, a irrupção de atores do setor privado, tanto do mercado quanto da sociedade civil, e a consequente complexificação das relações internacionais (HURRELL; KINGSBURY, 1992; GREEN, 2014; KAVALSKI, 2016; LE PRESTRE, 2017).

A sociedade civil é entendida como criadora de processos objetivando construir consensos; a arena onde os indivíduos lutam, negociam ou debatem entre si e com os centros de autoridade política e econômica (instituições globais, organizações internacionais e empresas). É uma plataforma habitada pelos mais diversos atores que integram não como "uma sociedade civil global" como Keane (2003) a descreveu, mas várias sociedades civis com autonomia e autoorganização (KALDOR, 2003).

Held et al. (2002) evidenciaram que, nas últimas três décadas, houve a ampliação de uma gama de desafios ambientais, levando o debate sobre desenvolvimento sustentável a uma perspectiva global. Em outros termos, desafios ambientais tratados anteriormente como questões domésticas foram internacionalizados sob os conceitos de "interdependência ecológica" (LITFIN, 1999) e desenvolvimento sustentável ao longo do século XX, principalmente após o final da ordem de Yalta. Temas mais específicos como florestas e proteção de espécies ameaçadas hodiernamente recebem tratamento na agenda multilateral como temas efetivamente globais, como também mudança do clima, água, gestão da biodiversidade terrestre e marinha, acidentes nucleares, serviços ecossistêmicos, entre outros. Destaca-se nessa perspectiva a Organização das Nações Unidas (ONU) como uma das arenas mais importantes do debate multilateral, espaço político no qual se estabelecem eventuais acordos entre os atores soberanos, desenhando um esboço de governança ambiental global (ALFAIA JR., 2014).

Neste contexto evolutivo, o processo de privatização das relações internacionais está diretamente ligado àquele da globalização da agenda ambiental. Com a facilitação do acesso à tecnologia de comunicação e informação, a participação de atores cívicos, notadamente $\mathrm{ONG}$, aumentou substancialmente nos processos decisórios ao redor do mundo, dentro e fora do sistema ONU. Da mesma forma, atores do mercado (empresários e consumidores) têm hoje 
maior capacidade de exercer influência nos processos decisórios relativos a temas socioambientais (JANG et al., 2016). Ademais, tais temas não são desconectados de temas econômicos e culturais, como demonstra o conceito de desenvolvimento sustentável.

Destarte, o processo de complexificação das relações internacionais, constitui uma tendência que já havia sido discutida por autores como Ruggie (1982), Keohane e Nye (1977) e Rosenau e Czempiel (2000). Não bastasse a complexidade dos seres vivos, somam-se a ela as interações entre a biosfera, atmosfera e os oceanos. Porém, o fator principal da complexificação é a ação política internacional para a construção de uma suposta ordem de desenvolvimento planetário sustentável. Isto implica afirmar que a proliferação das negociações multilaterais sob a égide da ONU conduziu a uma governança ambiental extremamente fragmentada, com diversos regimes superpostos que interagem, mas não são necessariamente coerentes (BARROS-PLATIAU; MALJEAN-DUBOIS, 2017).

Nessa perspectiva o objetivo do estudo reside no desafio em descortinar as possibilidades de ganhos intangíveis decorrentes das reiteradas Conferências da ONU. A metodologia está centrada na discussão e institucionalização das decisões relativas à temática ambiental, e assim estabelece como referência as Conferências ambientais das Nações Unidas, de 1972 a 2012. A Conferência das Nações Unidas sobre Desenvolvimento Sustentável, a Rio $+20^{2}$, contribuiu para definir a agenda do desenvolvimento sustentável para as próximas décadas. Porém, predomina uma percepção generalizada que a conferência fracassou, pois não atingiu objetivos ambiciosos e concretos. Mas não teria obtido êxito e gerado ganhos intangíveis ${ }^{3}$ junto à comunidade internacional?

Assim, tendo como referência as Conferências das Nações Unidas e o fluxo de informações decorrentes da Rio+20, na perspectiva de responder ao desafio proposto, o estudo está organizado em três partes, inicialmente

2 Conferência das Nações Unidas sobre Desenvolvimento Sustentável, que teve como objetivo a renovação do compromisso político com o desenvolvimento sustentável, por meio da avaliação do progresso e das lacunas na implementação das decisões adotadas pelas principais cúpulas sobre o assunto e do tratamento de temas novos e emergentes. A Conferência teve dois temas principais: a economia verde no contexto do desenvolvimento sustentável e da erradicação da pobreza; e a estrutura institucional para o desenvolvimento sustentável. (ONU, 2012c)

3 O dicionário da Oxford University Press define o verbete Intangível (adj.2g.) como: 1 que não se pode tanger, tocar, pegar; intocável. 2 não perceptível pelo tato; impalpável, incorpóreo <música de sons etéreos, i.> | <uma visão etérea, i.> 3 fig. que não é suficientemente claro ou definido para ser percebido ou entendido; que elude a percepção ou o entendimento <argumento i.> | <tema i.> 4 fig. que, por seu valor e dignidade, não pode ser atacado e deve permanecer intato, inalterado; inatacável, indestrutível <os dogmas são i.para os que neles creem $>$. Neste artigo, utilizaremos o sentido de que intangível é algo que não é suficientemente claro ou definido para ser percebido ou entendido; que elude a percepção ou o entendimento. 
apresenta as questões relativas à agenda ambiental global. Traz na segunda parte reflexões sobre a tríade Rio+20, mídia e a esfera pública digital; e por fim as considerações acerca do tema do desenvolvimento sustentável e os resultados decorrentes da Rio +20 .

\section{A AGENDA GLOBAL DE DESENVOLVIMENTO SUSTENTÁVEL}

Pensar o desenvolvimento não é uma tarefa fácil, pois sua própria definição depende das percepções e interesses de diferentes atores. Diante deste desafio, alguns esforços teóricos podem apontar o que não é desenvolvimento. Além da crítica ao reducionismo economicista que forjou a primeira ideia de desenvolvimento, merece destaque a crítica - talvez mais avessa e profunda - de que as disputas no sistema internacional moldaram a perspectiva do que poderia ser a ideia de desenvolvimento. Essa posição é inaugurada no desenrolar da pax americana em 1949, quando o presidente dos Estados Unidos, Harry Trumam, usou a palavra subdesenvolvimento e mudou o significado de desenvolvimento, criando assim um eufemismo que aludiria à era da hegemonia norte-americana (ESTEVA, 2010).

Never before had a word been universally accepted on the very day of its political coinage. A new perception of one's own self, and of the other, was suddenly created. Two hundred years of social construction of the historical-political meaning of the term 'development' were successfully usurped and transmogrified. A political and philosophical proposition of Marx, packaged American-style as a struggle against communism and at the service of the hegemonic design of the United States, succeeded in permeating both the popular and the intellectual mind for the rest of the century (ESTEVA, 2010, p. 2) ${ }^{4}$.

Esteva (2010) afirma que Truman não foi o primeiro a usar o termo subdesenvolvimento. Isso já havia sido feito por burocratas, políticos, bem como constava em documentos das Nações Unidas. Porém, só teve repercussão e relevância quando Truman o empregou como marca de sua própria política, adquirindo assim virulência colonizadora insuspeita.

\footnotetext{
Nunca antes uma palavra havia sido universalmente aceita no próprio dia de sua cunhagem política. Uma nova percepção de si mesmo e a outra foi subitamente estabelecida. Duzentos anos de construção social do significado histórico-político do termo "desenvolvimento" foram objetos de usurpação bem-sucedida e metamorfose grotesca. Uma proposta política e filosófica de Marx, embalada no estilo americano como luta contra o comunismo e ao serviço do design hegemônico dos Estados Unidos, conseguiu permear a mentalidade popular, bem como a letrada, para o resto do século (nossa tradução).
} 
Desenvolvimento talvez signifique o desenrolar, desdobrar uma capacidade que possa evidenciar as dimensões cooperativa e competitiva, verificar como uma potencialidade foi dinamizada. A teoria econômica clássica cometeu, no passado distante, o equívoco ao apontar desenvolvimento como sinônimo de crescimento, como uma equação linear onde X determinaria Y. Desenvolvimento pode ser visto a partir de uma multidimensionalidade cujos elementos se combinam dentro de um processo de determinação e condicionamento. Pode inclusive ser visto como "liberdade". Esses elementos podem ser o crescimento, a cooperação, o ambiente físico-territorial, político, social, tecnológico dentre outros que se apresentam. No entanto, apesar de conhecermos estes elementos, não sabemos como eles se relacionam para formar um círculo virtuoso de mudanças que leve ao desenvolvimento, inclusive ao desenvolvimento humano medido pelo Programa das Nações Unidas sobre Desenvolvimento (índice IDH) (FRANCO, 2002; SEN, 2010).

Desta forma, podemos compreender a ideia de desenvolvimento sustentável a partir da perspectiva de uma preocupação global formada dentro das arenas do sistema internacional. O conceito do desenvolvimento sustentável rechaça o economicismo e, ao mesmo tempo, assenta-se na cooperação, no investimento nas pessoas, no respeito ao ambiente natural e em outros capitais que não sejam necessariamente o financeiro. No documento Nosso Futuro Comum reside, assim, o princípio de desenvolvimento sustentável:

O desenvolvimento sustentável é aquele que atende as necessidades do presente sem comprometer a possibilidade das gerações futuras atenderem às suas próprias necessidades [...] Satisfazer as necessidades e as aspirações humanas é o principal objetivo do desenvolvimento (NOSSO FUTURO COMUM/COMISSÃO MUNDIAL SOBRE DESENVOLVIMENTO 1991, p.46).

No relatório da Comissão sobre Governança Global, a proteção do meio ambiente constitui uma questão profundamente importante. É destacada a ideia de que o meio ambiente é o liame social e, desta forma, a humanidade tem um futuro comum. Assim, o desenvolvimento sustentável deve ser uma referência, um orientador da conduta de todos os Estados desenvolvidos e em desenvolvimento. Se o desenvolvimento contribui para a governança global, é possível que se chegue ao desenvolvimento sustentável global (COMISSÃO SOBRE GOVERNANÇA GLOBAL, 1996). Se somássemos as duas visões, do Nosso Futuro Comum com a do Relatório sobre Governança Global, chegaríamos ao desenvolvimento como processo de expansão da liberdade, firmado no desenvolvimento de uma liberdade substantiva que inclui capacidades 
elementares garantidoras da sustentabilidade da vida (SEN, 2010). Assim e na mesma linha, "desenvolvimento tem a ver, com a possibilidade de as pessoas viverem o tipo de vida que escolherem, e com a provisão dos instrumentos e das oportunidades para fazerem suas escolhas" (VEIGA, 2015, p. 82).

No desenrolar deste debate e no contexto pós-Rio 92, a visão que a sociedade civil tem sobre o desenvolvimento sustentável é positiva e promissora, mas sem abandonar o espírito crítico que prevaleceu na Rio +5 , por exemplo. Primeiro porque a agenda de participação internacional da sociedade civil avança, inclusive na promoção do Acordo de Paris sobre Mudança do Clima e da Agenda sobre Objetivos de Desenvolvimento Sustentável (2030), ambos de 2015. Segundo porque esse conjunto de atores privados vê com muita expectativa a mudança de padrão da relação capital e natureza, e isso pode ser visto na maior ampliação da participação da sociedade civil durante os eventos oficiais sobre desenvolvimento na ONU - 300 mil pessoas se reuniram na Cúpula dos povos e quase 800 mil ao todo na Rio+20 (ONU, 2012b).

Entre as reflexões da representação da sociedade civil nos espaços de participação na discussão sobre desenvolvimento sustentável, para além das questões conjunturais e imediatas, projeta-se uma visão de longo prazo na qual,

devemos entender que mais importante do que esta série de eventos é o processo no qual se inserem. Nosso horizonte é o day after, é o longo caminho que culminará quando a sustentabilidade do desenvolvimento seja uma realidade sentida e vivida por cada cidadão, e não pelos poucos que disputam os benefícios de uma globalização excludente (FBOMS, 1997, p. 27).

Para além das controvérsias e da precaução com a ideia de desenvolvimento sustentável, Giddens (2016) reafirma a combinação da conservação do meio ambiente natural com o desenvolvimento econômico, evidenciando a periferia e a semiperiferia do capital. Reconhece a institucionalização do conceito de desenvolvimento sustentável no Relatório Brundtland (Nosso Futuro Comum), de 1987, mas afirma que tal conceito já se encontrava, no século XVIII, na relação entre população e alimentação estabelecida por Malthus, e no crescimento excessivo da economia que prejudicaria a qualidade de vida e o meio ambiente em John Stuart Mill. "Aquilo que Malthus e Mill buscavam era o que hoje chamamos, na linguagem moderna, de desenvolvimento sustentável" (GIDDENS, 2016, p. 78).

Impondo-se a partir de um processo globalizado que territorializa, reterritorializa, desterritorializa os espaços dos Estados nacionais, transversaliza outros temas importantes para estabilidade das sociedades humanas, a agenda de desenvolvimento sustentável foi debatida nas arenas das Organizações das 
Nações Unidas, começando em Estocolmo (GALVÃO; NASCIMENTO, 2014). A Conferência de Estocolmo foi a primeira Conferência das Nações Unidas sobre o Meio Ambiente Humano "atenta à necessidade de um critério e de princípios comuns que ofereçam aos povos do mundo inspiração e guia para preservar e melhorar o meio ambiente humano". Realizada de 5 a 16 de junho de 1972, obteve como resultado a Declaração de Estocolmo, que reúne 26 princípios que marcaram o início da busca por uma conciliação entre práticas de preservação ambiental e desenvolvimento (ONU, 1972). Iniciada e liderada pelos países desenvolvidos, a Conferência colocou as questões ambientais definitivamente nas agendas multilaterais. Porém, um dos maiores resultados de 1972 foi o aprofundamento da clivagem Norte versus Sul em função da carência de uma visão compartilhada de direitos e deveres (LE PRESTRE, 2000).

Em paralelo aos debates sobre meio ambiente e soberania, em 1982 foi assinada a Convenção das Nações Unidas sobre Direito do Mar (ONU, 1982), reforçando o fato de que o tema "oceanos" geralmente foi tratado às margens das grandes conferências ambientais.

Em junho de 1992 foi realizada no Rio de Janeiro a Conferência das Nações Unidas sobre Meio Ambiente e Desenvolvimento, a Eco-92, que contou com a participação de 172 países, incluindo 108 chefes de estado, além de mais de 2.400 representantes de organizações não-governamentais e de 17.000 participantes dos eventos paralelos organizados por ONG. Cerca de 10.000 jornalistas fizeram a cobertura do evento. Milhões de pessoas acompanharam pela imprensa mundial a Eco-92 (ONU, 2012a). É de bom alvitre destacar que 1992 pode ser considerado o ano de fechamento de um ciclo de negociações multilaterais complexas, o que contribuiu em larga medida para a construção de consenso que engendrou duas convenções-quadro (clima e diversidade biológica), duas declarações (princípios e florestas) e a Agenda 21. Esta última está diretamente ligada à Agenda de Objetivos de Desenvolvimento do Milênio (Agenda ODM de 2000 a 2015) e à Agenda de Desenvolvimento Sustentável (Agenda ODS de 2015 a 2030).

Em ato seguinte, em 1997, foi realizada em New York a Cúpula da Terra +5 (ou Rio+5) numa sessão especial da ONU, ocasião em que foi discutida a Agenda 21 com recomendações de implementação, bem como as mudanças climáticas e a erradicação da pobreza com vista à realização do desenvolvimento sustentável. Paralelamente, no Rio de Janeiro, organizações da sociedade civil discutiam e trocavam experiência no Fórum Rio+5 (EM DISCUSSÃO, 2012) no sentido de compreender o conceito de desenvolvimento sustentável com vista a sua realização concreta. 
Com o fito principal de reafirmar os compromissos da Cúpula do Rio, em setembro de 2002 foi realizada a Cúpula Mundial Sobre Desenvolvimento Sustentável ou Rio+10, em Joanesburgo, África do Sul. Convém sublinhar que em 1972 o título da conferência trazia "meio ambiente humano", ao passo que em 1992 foi "meio ambiente e desenvolvimento"; depois "Cúpula de desenvolvimento sustentável” em 2002. Esta evolução demonstra a maior integração do conceito de desenvolvimento sustentável nas políticas discutidas na arena multilateral. O documento final de 2002, assinado pelos representantes de todos os Estados-Membros da ONU presentes, incluiu a demanda pelo alívio da dívida externa dos países em desenvolvimento, o aumento da assistência financeira para os países menos avançados. Além disso, reconheceu que os desequilíbrios e a má distribuição de renda, tanto entre países quanto dentro deles, estão no cerne do desenvolvimento insustentável (LORENZET'TI, 2002; LAGO, 2006).

Em um passo adiante, visando definir a agenda do desenvolvimento sustentável para as próximas décadas, realizou-se a Rio +20 , promovida pelo Brasil, cujos resultados passamos a examinar. Entre 1972 e 2012, merecem destaques alguns ganhos tangíveis e intangíveis, formando um denso continum. Do ponto de vista institucional, a criação do Programa das Nações Unidas para o Meio ambiente (PNUMA), com sede no Quênia, bem como a criação de ministérios em diversos países durante a década de 1970 contribuiu para a inserção de temas relativos a desenvolvimento sustentável nas agendas nacionais e multilaterais (LE PRESTRE, 2000). Além disso, a ratificação de inúmeros tratados ambientais multilaterais e temas afins, formando um verdadeiro "complexo de regimes" em poucas décadas, estruturou a governança global, sob liderança euro-atlântica (BOULET et al., 2016).

Entre os ganhos intangíveis, mesmo que inseparáveis dos ganhos tangíveis, cabe ressaltar a crescente participação dos atores não-estatais (privatização), inclusive da comunidade científica e setores empresariais, com destaque para iniciativas como a Global Compact. O aumento da preocupação da sociedade em geral com as questões da sustentabilidade - aqui considerados como ganhos intangíveis - tem provocado mudança no comportamento das empresas, que passaram a buscar soluções mais aceitáveis (GRANDELLE, 2014), como por exemplo, o investimento em energias limpas e produção alimentar orgânica. Essa mudança impacta estratégias empresariais, à medida que os consumidores, buscam produtos mais sustentáveis, e assim desafiam as empresas a buscarem produtos inovadores e novos modelos de negócios capazes de criar imagem

5 Ver Orsini, Morin e Young (2014) sobre o conceito. 
e construir reputações (MARKET RESEARCH BLOG, 2017). Entretanto, o capitalismo de hiperconsumo demanda hipervisibilidade das marcas, onde a dimensão do imaterial se sobrepõe à dimensão material, criando uma identidade ou uma cultura da marca por meio de ferramentas de comunicação e marketing (LIPOVETSKY; SERROY, 2011).

Essa maior consciência das questões ambientais resultante da agenda multilateral também é percebida no Brasil e tem mudado o comportamento da classe política, porém de forma assaz assimétrica e irregular. Estudos de Galvão e Nascimento (2014) comprovaram que, transversalmente, todos os partidos que disputaram as capitais dos estados da Amazônia legal nas eleições municipais de 2012 assimilaram elementos da agenda ambiental em seus programas de governo, num processo pedagógico tanto para partidos quanto para eleitores:

Apesar da significativa participação nos programas de governo dos candidatos a prefeitos das capitais da Amazônia Legal, as evidências apontam no sentido de que estas cumprem mais uma função estratégica do ponto de vista da captura discursiva do eleitor do que efetivamente uma intenção a ser cumprida. Do ponto de vista do eleitorado, este acaba passando por um processo de aprendizado baseado na experiência, tornando-se cada vez mais exigente. A classe política também aprende e se adapta à nova realidade imposta. Como os políticos visam à reeleição (ou a eleição de seus sucessores), estes terão que executar, pelo menos em parte, o que prometeram (GALVÃO; NASCIMENTO, 2014, p. 36).

Por fim, esse processo histórico de estruturação da agenda de desenvolvimento sustentável se completa, amplia-se e dinamiza o horizonte futuro de resultados com os instrumentos de planejamento de longo prazo. Já mencionado, a Agenda 21, elaborada na Rio-92; Agenda de 2000-2015 (Objetivos de Desenvolvimento do Milênio) e; Agenda seguinte, até 2030 (Objetivos de Desenvolvimento Sustentável) são parte de um longo processo multilateral. Estas são, indubitavelmente, fontes preciosas dos ganhos intangíveis obtidos desde 1972 e dos novos riscos assumidos com a "complexificação" das relações internacionais segundo Kavalski (2016), analisado a seguir a partir da esfera pública digital.

\section{A RIO+20, MÍDIA E A ESFERA PÚBLICA DIGITAL}

A esfera pública é o espaço de discussão e do debate público das sociedades modernas, de intersecção entre os interesses dos grupos da sociedade civil e do Estado a partir de processos dialógicos deliberativos capazes de garantir legitimidade às políticas públicas e o melhor interesse público (GIDDENS; SUT'TON, 2016). 
"Ela se torna a arena onde se dá tanto a amálgama da 'vontade coletiva' quanto a justificação de decisões políticas previamente acertadas" (COSTA, 1995, p. 55).

Costa (1995), ao analisar o modelo teórico-discursivo de esfera pública, observa que os atores da sociedade civil diferem dos demais quanto ao conteúdo, uma vez que tematizam situações-problemas relevantes para toda a sociedade, emergentes na vida cotidiana. Também diferenciam quanto às formas de comunicação, pois buscam transformar a esfera pública numa arena de argumentação discursiva e de convencimento do conjunto da sociedade sobre a justeza de seus propósitos. Esses esforços comunicativos resultam em poder quando as mensagens transmitidas encontram ressonância na sociedade.

A esfera pública é o espaço que a sociedade civil dispõe para exercer influência sobre o processo político. Por isso, busca explorar intensivamente as possibilidades comunicativas existentes e ampliar as fronteiras dessa esfera, a partir da incorporação de novas minorias e grupos marginais e da invenção de novos meios comunicativos, contribuindo com a reprodução e revitalização da esfera pública (COSTA, 1995). No nível multilateral, o mesmo processo pode ser observado, com destaque para a atuação de atores como políticos de destaque (Al Gore, Arnold Schwarzenegger), comitês internacionais (Prêmio Nobel), Fundações (Bill e Melinda Gates, Bill Clinton) e cientistas (IPCC e diversas outras formas de interação público-privada).

Castells (2013) já observara que os movimentos sociais em rede ao redor do mundo têm exigido uma nova forma de democracia, que possibilite administrar de forma coletiva nossas vidas de acordo com princípios amplamente compartilhados em nossas mentes e que são, em geral, negligenciados no quotidiano. $\mathrm{O}$ autor considera que esses movimentos sociais em rede configuram novos tipos de movimento democrático, que estão reconstruindo a esfera pública no espaço de autonomia constituído em torno da interação entre localidades e redes da internet, num processo de recomeço, moldando mecanismos de participação política.

Nye (2009) ressalta que a interatividade a baixo custo, possibilitada pela ampliação do acesso à internet, permite o desenvolvimento de novas comunidades virtuais que aglutinam pessoas que, mesmo distantes fisicamente, sentem-se integrantes de um mesmo grupo. Essas comunicações transnacionais tornaram as fronteiras mais permeáveis e contribuem para a constituição dessa sociedade em rede, onde o poder é multidimensional - e se organiza em torno de redes programadas em cada domínio da atividade humana - e é exercido influenciando a mente humana mediante as redes multimídia de comunicação de massa, fontes decisivas de construção do poder (CASTELLS, 2013). 
A constituição de redes é operada pelo ato da comunicação. Comunicação é o processo de compartilhar significado pela troca de informações. Para a sociedade em geral, a principal fonte da produção social de significado é o processo da comunicação socializada. Esta existe no domínio público, para além da comunicação interpessoal. A contínua transformação da tecnologia da comunicação na era digital amplia o alcance dos meios de comunicação para todos os domínios da vida social, numa rede que é simultaneamente global e local, genérica e personalizada, num padrão em constante mudança (CASTELLS, 2013, s/n).

Castells (2013) aponta que os movimentos sociais, para além do processo comunicativo com a sociedade em geral, precisam construir um espaço público - situado entre os espaços digital e urbano - que não se restrinja à internet, mas que dê visibilidade nos lugares da vida social, uma vez que o espaço público institucional está ocupado pelos interesses das elites dominantes e suas redes. Daí a importância de se ocupar o espaço urbano e os prédios simbólicos. A participação dos movimentos sociais nas conferências da ONU - espaço público institucional designado para a deliberação - não viria a ser a domesticação desses movimentos? Diz o autor que as redes de contra-poder devem reprogramar qualquer dimensão que pretendam mudar (a organização política, a economia, a cultura etc.), introduzindo nos programas das instituições e em suas próprias vidas outras instruções - inclusive versões utópicas -, para que prevaleçam sobre as redes de poder embutidas na organização da sociedade. Também precisam estabelecer conexão entre diferentes redes de mudança social.

Marques (2006), ao examinar teoricamente algumas das dimensões da interface entre democracia e novas tecnologias digitais de comunicação e informação, mais especificamente as possibilidades de estabelecimento de uma versão virtual do espaço discursivo que é a esfera pública, conclui que a esfera pública virtual é um espaço de conversação civil, atuando de modo mais eficaz como espaço destinado à formação complementar de opiniões do que como um espaço decisório por excelência. A forma democrática de governo tem, assim, nas redes telemáticas, um canal alternativo para fomentar a participação dos cidadãos.

Assim, complementa Marques (2006), observa-se que muitos debates só se concretizam por causa do advento da internet. Bem ou mal, o ambiente digital possibilita a exposição de opiniões e formação de arenas conversacionais. "O fato é que o modelo de esfera pública que exige dos cidadãos um engajamento e racionalidade constantes parece ser pouco correspondente à realidade social contemporânea", sentencia Marques (2006, p. 183).

Destarte, a Rio +20 pode ser entendida a partir do conceito habermasiano de esfera pública global, caracterizada por processos de participação e 
aprendizagem, a partir do qual se firmam ganhos intangíveis. Essa conferência, assim como outros eventos globais históricos (Estocolmo 72, Rio 92, Rio+5, Rio+10, Rio+20, entre outros), podem auxiliar na compreensão de um problema global, qual seja: os efeitos deletérios do homem e seu sistema produtivo sobre o meio ambiente, que levou ao conceito de Antropoceno.

Assim, e apesar do contexto desfavorável para a assunção de novos compromissos multilaterais, a Rio +20 foi realizada na cidade do Rio de Janeiro, de 13 a 22 de junho de 2012. Foram mais de 100 países representados por autoridades, incluindo 57 Chefes de Estado, 08 Vice-Presidentes, 31 Chefes de Governo, 09 Primeiros-Ministros, 487 ministros e 30 mil participantes. Foram 498 eventos paralelos ao longo dos dez dias da Conferência (ONU, 2012b). Apesar desses números, a Conferência foi considerada por alguns um fracasso que estava anunciado. Tal fracasso se deveu pela crescente distância entre os problemas de interdependência e os mecanismos globais de governança existentes, resultantes de um sistema internacional dominado por forças soberanistas e conservadoras, reticentes a ceder poder e renunciar a interesses de curto prazo na busca da construção de bens públicos globais sustentáveis (GUIMARÃES; FONTOURA, 2012; VIOLA; FRANCHINI, 2012)

A Rio+20 manifesta-se como evidência clara dessa defasagem entre crise sistêmica; consciência pública global sobre o problema, que se expande progressivamente; e resposta diplomática extremamente conservadora e ineficiente. A Cúpula foi um fracasso desde o ponto de vista da evolução dos mecanismos cooperativos para promover a gestão sustentável dos recursos compartilhados, chamados "bens comuns globais", e um fracasso ainda maior se consideradas as evidências científicas sobre a degradação do sistema terrestre acumuladas neste período (VIOLA; FRANCHINI, 2012). E ainda mais desastroso se considerarmos o aumento da capacidade destrutiva das armas nucleares desde 1972, principalmente nas potências europeias que supostamente promovem o discurso ambiental.

Em parte, o fracasso da Rio +20 deu-se em decorrência da crise financeira iniciada nos EUA em 2007, que demandou aporte bilionário de recursos do governo americano e dos governos europeus para salvar seus sistemas financeiros. Isso impactou fortemente a construção dos regimes internacionais, aqui entendidos como princípios, normas e procedimentos decisórios em torno dos quais converge a expectativa dos atores em certas áreas temáticas (KRASNER, 2012). A Rio+20, da perspectiva de construção de regimes ambientais nos últimos 40 anos, parece não fugir desta tendência. Desta forma, quando os atores envolvidos na construção dos regimes percebem a falta de liderança que decorre 
da ação direta do hegemon e de seus círculos de influência, também se afastam das obrigações internacionais (VIOLA; FRANCHINI, 2018). Entretanto, o sociólogo e embaixador Luiz Felipe Lampreia (2012) discordou da avaliação de que a Rio+20 foi um fracasso:

É porém injusto dizer que uma reunião na qual houve tantos debates paralelos, tantos encontros científicos, tantas análises inteligentes e manifestações múltiplas terá sido um fracasso. A consciência do imperativo da sustentabilidade certamente multiplicou-se e ganhou mais convencidos. Tal resultado não é tangível mas é real, mesmo no momento em que a crise econômica internacional desvia as atenções dos dirigentes para outros horizontes. Esta percepção demora a penetrar as mentes das sociedades e dos políticos mas vai, cada vez mais, tornar-se evidente em razão de fenômenos climáticos que danificam as culturas agrícolas e desequilibram a oferta de alimentos, em virtude dos danos ambientais que a televisão nos mostra diariamente e dos riscos cada vez mais palpáveis que nosso planeta enfrenta. Por isso tudo, eu diria que a Rio+20 foi um passo na direção certa (LAMPREIA, 2012, s.p.).

A Rio+20 ficou marcada pela adoção de uma plataforma inovadora na discussão sobre desenvolvimento sustentável. Com os Diálogos para o Desenvolvimento Sustentável, realizou-se pela primeira vez em conferências das Nações Unidas um processo participativo e inclusivo que possibilitou aos representantes da sociedade civil apresentar recomendações ao Segmento de Alto Nível da Conferência. Os Diálogos consistiram em dez rodadas de discussão, com dez participantes em cada uma, que abordaram temas prioritários da agenda internacional de sustentabilidade. Foram conduzidos durante a Rio +20 , no Riocentro, entre 16 e 19 de junho, e os temas debatidos em cada painel foram escolhidos por pessoas de diversas partes do mundo por meio da internet. Iniciado em abril de 2012, esse processo envolveu cerca de 30 representantes de universidades e centros de pesquisa no mundo que coordenaram discussões abertas pela internet. O processo de participação da sociedade civil teve início por meio da discussão demais de 500 recomendações propostas na Plataforma Digital dos "Diálogos para o Desenvolvimento Sustentável". As que tiveram maior nível de apoio foram levadas para votação, entre 5 e 15 de junho, no site aberto. Internautas de todo o mundo puderam contribuir votando nas 100 recomendações propostas pela plataforma. Mais de 63.000 pessoas de 193 países participaram com cerca de 1,4 milhão de votos (RIO+20, 2012).

Segundo Luhmann (2000) em Oliveira e Reis (2013, p. 239), comunicação ocorre entre sistemas quando um sinal surge e a informação referente impacta um sistema específico, que se reorganiza, incorporando essa informação e 
promovendo a comunicação. Para o autor, "o que existe na formação da opinião pública moderna é uma seleção de temas, cujo tempo de vida é muito curto, acelerando o processo de seleção de qual tema estará em voga". Para ele, a opinião pública não é entendida como o produto de um sistema, e sim das múltiplas interações necessárias à “autopoiese " do sistema político. Oliveira e Reis (2013), ao analisarem mensagens relacionadas à marca Rio nos ambientes broadcast e socialcast e veiculadas durante a Rio +20 , identificam que a convergência das informações nos contextos do brodcast e do socialcast promove a visibilidade em massa de temas que muitas vezes não são selecionados pelos chamados"sistemas" de Luhmann, mas pelo interesse demonstrado pelos grupos engajados e articulados nas redes sociais. Assim, tendencialmente pode se afirmar que o debate que ocorre nessa esfera pública digital pauta cada vez mais os temas que serão selecionados pelos meios de comunicação de massa.

No Broadcast (do inglês, transmissão) a informação sai de uma fonte emissora e chega a uma grande massa de receptores. Para isso é preciso haver um intenso investimento das empresas em criar tecnologia que alcance um número maior de pessoas. Portanto, o capital é fator determinante na manutenção desse método. Já no Socialcast, a informação sai de uma grande massa e chega a outra grande massa, onde todos tem o poder de transmitir uma informação ou dar um furo de notícia. $\mathrm{O}$ Socialcast não exige licenças e muda o posicionamento da publicidade e do capital. Ele quebra a barreira de tempo e espaço e dispensa plataformas fixas (ABDALLA, 2011, s.p.).

Ely (2013) fez uma análise dos discursos proferidos na rede social Facebook durante a Rio +20 , buscando compreender a importância da comunicação em rede na sociedade contemporânea e analisar como a sustentabilidade é disseminada pelas redes sociais digitais. A partir da análise dos discursos proferidos sobre o tema, a autora buscou compreender que movimentos são gerados discursivamente, e qual o caráter dessas conversações, concluindo que, apesar das redes sociais possibilitarem acesso a informações e conectarem as pessoas, isso não leva a um aumento da efetividade das ações relacionadas à sustentabilidade. "Simplesmente, é mais um espaço criado e disponibilizado para lançar propostas, gerar conversas e mobilizar debates. Portanto, constitui-se em um espaço mais de ideias do que de práticas”, completou a autora.

Quando se fala de sustentabilidade, os atores que participam do processo - seja na rede ou fora dela - são empresas, governos, organizações não governamentais, entidades civis, instituições de ensino públicas e privadas,

\footnotetext{
Termo criado pelos biólogos chilenos Humberto Maturana e Francisco Varela para designar a capacidade de criação e recriação dos sistemas viventes.
} 
personalidades do mundo pop, defensores dos animais, membros de comunidades, acadêmicos, filósofos ou cidadãos comuns, que expressam seu simples desejo ou ponto de vista pessoal. E a mídia. Seja pelo viés da atuação institucional, seja pelo engajamento de alguns profissionais, seja por uma política de relacionamento com a audiência, a mídia está conectada mais do que nunca nos debates e conversas sobre o tema da sustentabilidade. Entre os tipos de discursos mais recorrentes, encontramse aqueles que divulgam ideias, questionam conceitos, criam eventos e articulam manifestações. Existem ainda os que satirizam e ironizam certas situações. O mais interessante e salutar do processo da digitalização dos discursos políticos e sociais é que todos esses atores e seus discursos coexistem no mesmo espaço (ELY, 2013, p. 38).

Apesar dos avanços na cobertura jornalística de eventos ambientais, especialmente após a Eco 92, alertam Sabbagh e Reis (2014) que os depoimentos, a análise dos textos do Jornal de Santa Catarina, a bibliografia e os artigos evidenciam que, de maneira geral, a grande mídia e a imprensa latino-americana "divulgam mal e, pior que isso, de maneira superficial a problemática ambiental, concentrando foco apenas nos casos dramáticos e factuais", evidenciando uma ausência de preocupação maior em pautar "uma agenda regular, qualificada e propositiva pela ampliação da consciência ambiental, do desenvolvimento sustentável, da proteção premente dos ecossistemas e a luta pela qualidade de vida das atuais e futuras gerações e de todos os seres vivos" (SABBAGH; REIS, 2014, p. 11).

Os números da Conferência impressionam: mais de 45.000 participantes; delegações de 188 Estados-Membros e três observadores; mais de 100 Chefes de Estado e de Governo; aproximadamente 12.000 delegados e 9.856 ONGs e Major Groups. Um custo de R\$97,1 milhões. Durante a Rio+20, a Cidade recebeu 110 mil turistas, os hotéis tiveram taxa de ocupação de 95\% e o Comércio cresceu 6\%. Do ponto de vista da comunicação, os números são mais impressionantes ainda: mais de 4 mil jornalistas fizeram a cobertura no Rio de Janeiro; mais de 160 mil matérias foram publicadas sobre a Rio+20 no mundo todo; mais de 50 milhões de pessoas compartilharam ou visualizaram ideias e pensamentos sobre desenvolvimento sustentável e o futuro que elas querem; foram geradas no Twitter mais de um bilhão de impressões com\#Rioplus20, além de mais de um milhão de pessoas no Facebook (ONU, 2012b).

Para compreender a relevância desses números, precisamos atentar para as transformações ocorridas na dimensão cultural do mundo globalizado. Lipovetsky e Serroy (2011) sentenciam que um regime inédito de cultura emergiu com o novo ciclo de modernidade que recompõe o mundo atual. A este novo 
ciclo eles denominam de hipermodernidade, organizado em torno de quatro polos estruturantes: hipercapitalismo, hipertecnicização, hiperindividualismo e hiperconsumo. Essa hipermodernidade seria responsável pela transformação estrutural da cultura. "Ela se tornou mundo, uma cultura-mundo, a do tecnocapitalismo planetário, das indústrias culturais, do consumo total, das mídias e das redes digitais. [...] uma espécie de hipercultura universal que [...] reconfigura o mundo em que vivemos e a civilização por vir" (LIPOVETSKY; SERROY, 2011, p. 7). Os autores entendem que, com esta nova configuração de cultura, aumentou a consciência planetária dos perigos e o sentimento de viver em um mundo crescentemente interdependente.

Se é verdade que vivemos num mundo mais consciente desses perigos globais que nos afetam, também é verdade que as notícias que nos informam e atualizam desses perigos navegam no mar de informações que disputam nossa atenção todos os dias. "Não sofremos mais com a raridade do saber: estamos perdidos na própria abundância da informação" (LIPOVETSKY; SERROY, 2011, p. 22). A atenção é que se torna o recurso escasso e a credibilidade um recurso decisivo e importante de Soft Power. Há uma competição por narrativas num contexto onde informações que parecem ser propaganda pura mostram-se contraproducentes (NYE, 2009). Daí a importância de eventos globais como as conferências ambientais da ONU, com credibilidade e capacidade de disputar a atenção do público e que tragam a narrativa da agenda ambiental multilateral.

Os ganhos intangíveis decorrem dos rastros históricos deixados pelo processo de construção de regimes ambientais nos últimos 45 anos, muitas vezes encobertos pelas decisões que se institucionalizaram no sistema de Estados com os tratados multilaterais. Porém, quando inviabilizados, geram a falsa sensação de que não houve ganhos quanto às temáticas de desenvolvimento sustentável. Entretanto, o busílis da questão não é apenas de saber se houve acordo submetido a assinatura (hard law), mas sim quais foram os avanços intangíveis, alguns inclusive marcados por declarações, agendas e promessas coletivas ou individuais (soft norms). Em compromissos voluntários, a conferência mobilizou algo próximo de 513 bilhões de dólares e mais de 700 compromissos de grupos da sociedade civil, empresas, governos, universidades entre outros (ONU, 2012).

Os resultados intangíveis se corporificam com a participação intensa não só de atores estatais como também de atores não-estatais; com o grande fluxo de informações nos mais diversos meios de comunicação (imprensa tradicional, redes sociais na internet e outras mídias), sensibilizando a sociedade para que acompanhe as políticas públicas levadas a cabo pelo Estado. No caso de 45 anos de negociações e conferências onusianas, os ganhos intangíveis correspondem à 
ampla participação de atores não-estatais, como a rede transnacional do ICAN; aos avanços de consensos baseados na ciência, como no caso do IPCC e IPBES; à estruturação de novas formas de se fazer política, como as coalizões tipo high ambition group do clima que possibilitou a assinatura do acordo de Paris em 2015, e principalmente à possível revitalização da dinâmica multilateral, para que todos os compromissos assumidos formalmente sejam efetivamente observados, como no caso do desarmamento nuclear. Pensando em 2017 e na resistência das potências nucleares apoiadas pela OTAN, o tratado de abolição total de armas nucleares tem pouca chance de se tornar efetivo. Mas, pensando nos ganhos intangíveis desde 1972 que podem mobilizar os cidadãos que querem deixar para as gerações futuras um Planeta mais seguro e pacífico, talvez não.

\section{CONSIDERAÇÕES FINAIS}

Ao longo de quase cinco décadas floresceram espaços de governança - Estocolmo (1972), Rio-92 (1992), Joanesburgo (2002) e Rio+20 (2012) que estabeleceram desafios políticos, econômicos e sociais para mitigar as externalidades da atual crise ambiental.

A última das conferências, a Rio +20 , ficou marcada por ser considerada quase que unanimemente como um fracasso anunciado. Conforme observado, há ganhos intangíveis, mas reais. A experiência dos Diálogos Rio de convidar a todos para compartilhar perspectivas com líderes mundiais na Conferência iniciou uma tendência nas Nações Unidas, mostrando o valor de trazer todas as partes interessadas para enfrentar maiores desafios do mundo e inspirou novas rodadas de diálogos globais, tais como as consultas para o regime do clima, a Agenda ODS pós-2015, a Cúpula Mundial da Ajuda Humanitária, III Diálogos Habitat e a Assembleia Ambiental da ONU.

Outra dimensão dos ganhos intangíveis diz respeito ao processo de sensibilização da população para a agenda global. A imprensa mundial noticiou a Rio+20 de forma limitada, comentando sobre preparativos, expectativas, participantes e desafios. Durante o evento, fazendo a cobertura com flashes ao vivo, cadernos especiais, analistas e convidados. E após, fazendo balanços dos resultados, ouvindo especialistas e baseada nas publicações. De outro modo com os debates paralelos, encontros científicos, análises inteligentes e manifestações múltiplas contribuíram para fortalecer a consciência do imperativo da sustentabilidade e mobilizar esforços. Esse processo de sensibilização pode ter gerado mais engajamento de cidadãos mais diversos em todas as partes do mundo; deu visibilidade a temas que normalmente são ausentes da agenda, num 
processo onde essa nova esfera pública digital formada pelas redes sociais pauta temas de seu interesse. E é esse processo de sensibilização e conscientização permanente - que vem ocorrendo nas conferências ambientais internacionais que pode construir uma opinião pública mundial capaz de influenciar os atores globais a avançar rumo ao desenvolvimento sustentável.

As conferências sobre desenvolvimento ocorridas no âmbito ONU podem ser entendidas como uma dimensão importante na esfera pública global-lugar de participação, debate e aprendizado dos movimentos sociais em rede que se alastram pelo globo. Esse debate envolve a compreensão sobre o desenvolvimento numa perspectiva que o aproxime do ideal humanista do desenvolvimento sustentável.

Essa nova esfera pública dialógica global traz consigo a perspectiva de convivência harmônica do sistema capitalista com a preservação ambiental. $O$ diálogo sobre desenvolvimento, historicamente traçado, rompe com a ideia do crescimento econômico - numa intercessão com variáveis sociais, políticas, ambientais e tecnológicas - para pensar o desenvolvimento de outra forma, a forma sobre os quais se possa apontar para o desenvolvimento sustentável. As conferências sobre desenvolvimento têm proporcionado este debate que reúne atores estatais e da sociedade civil. Se compreendermos que a sociedade se articula em redes e esta ideia se materializa em ferramentas de comunicação em tempo real - as chamadas "redes sociais" -, podemos perceber que, ao longo do tempo, essa esfera tem se ampliado, visto que ela vai além do limite pontual dos protocolos articulados em torno da representação que ali se encontra, proporcionando informação para todo o globo. Essa esfera pública funciona, desta forma, numa dimensão cada vez mais digital. Se participação é a energia que alimenta esta arena, a vocalização através do ciberespaço é fundamental e estratégica, como demonstrados pela proliferação de mídias sociais articuladas em rede.

Uma alegoria interessante para pensar a esfera pública global seria o atirar de uma pedra na superfície de um lago de águas calmas. A perturbação causada pelo impacto da pedra na água gera um movimento de ondas de circunferências concêntricas que se afastam do ponto do impacto (o centro) para o exterior. Se pensarmos na esfera pública global com vista ao desenvolvimento sustentável, podemos vislumbrá-la como essa perturbação impulsionada e alimentada pela participação social em permanente diálogo com o Estado com vista ao melhor interesse público.

Ao laurear com a premiação do Nobel da Paz de 2017 uma ONG que militou pela proibição total das armas nucleares e, em 2007, o ex-vice-presidente dos Estados Unidos e ativista ambiental Albert Arnold (Al) Gore Jr. e o Painel 
Intergovernamental para Mudanças Climáticas (IPCC) da ONU por seus esforços para desenvolver e disseminar maior conhecimento sobre mudanças climáticas, o comitê reflete em suas decisões o processo de sensibilização da sociedade civil global (ou sociedades civis globais).

Considerando as conferências ambientais da ONU como dimensão da esfera pública global, podemos apontar, de imediato, a participação como um ganho social global. São essas conferências - como novas pedras atiradas no lago - que revigoram estes espaços, cujos resultados são o aprendizado com vista a criar mecanismos para resolução de um problema global: desenvolvimento de forma mais sustentável. A participação, além de ganho, é a retroalimentação de toda esfera pública. Os ganhos que advém desta participação fortalecida servem para o empoderamento da sociedade civil e como uma energia de reforço no sentido de apontar o diálogo e o aprendizado como as melhores estratégias para convencer os tomadores de decisão a agirem por meio da cooperação internacional. Um exemplo emblemático é a oposição de atores públicos e privados à decisão do presidente Trump de se afastar do Acordo de Paris. Esses ganhos - intangíveis - não podem ser vistos de forma isolada, mas a partir de uma forma processual que, a cada período, pode colher os frutos desejados na trajetória da participação na esfera pública global. Neste sentido, as conferências ambientais, em geral, foram muito exitosas.

\section{REFERÊNCIAS}

ABDALLA, Y. Mas afinal, o que é Socialcast? 2011. Disponível em: < https:/ / erasocialcast.wordpress.com/2011/09/23/mas-afinal-o-que-e-socialcast/ $>$. Acesso em: 30 jun. 2017.

ALFAIA JÚNIOR, J. R. Reclamar ou intervir? As obrigações positivas do Estado em situações de desastre ambiental. 2014. 309f., il. Tese (Doutorado em Relações Internacionais) - Universidade de Brasília, Brasília, 2014.

BARROS-PLATIAU, A. F.; MALJEAN-DUBOIS, S. La gouvernance globale de la biodiversité en haute mer. Enjeux juridiques de fragmentation et dé fragmentation. In: COMPAGNON, D.; RODARY, E. Politiques de la biodiversité. Presse de Sciences Po de Paris, 2017. p. 49-66.

BOULET, R.; BARROS-PLATIAU, A. F.; MAZZEGA, P. 35 years of Multilateral Environmental Agreements ratifications: a network analysis. Workshop Network Analysis in Law. Artificial Intelligence and Law, v. 24, n. 2, p. 133-148, June 2016. DOI 10.1007/s10506-016-9180-7. 
BRASIL. O que o brasileiro pensa do meio ambiente e do consumo sustentável. 2012. Disponível em: <www.mma.gov.br/images/noticias_ arquivos/pdf/sumarioexecutivo_pesquisabrasileiro_principais resultados_2012. pdf>. Acesso em: 19 jun. 2017.

Relatório Especial (A Rio +10 e os governos locais). Brasília, DF: Câmara dos Deputados, 2002. Disponível em: <http://www2.camara.leg.br/ documentos-epesquisa/publicaoes/estnottec/arquivos-pdf/pdf/pdf/209342. pdf $>$. Acesso em: 15 jun. 2017.

CASTELLS, M. Redes de indignação e esperança: movimentos sociais na era da internet. Trad.: Carlos Alberto Medeiros. Rio de Janeiro: Zahar, 2013

COMISSÃO MUNDIAL SOBRE MEIO AMBIENTE E DESENVOLVIMENTO. Nosso futuro comum. 2. ed. Rio de Janeiro: Editora da Fundação Getúlio Vargas, 1991.

COMISSÃO SOBRE GOVERNANÇA GLOBAL. Nossa comunidade global. Rio de Janeiro: Fundação Getúlio Vargas, 1996.

COSTA, S. A democracia e a dinâmica da esfera pública. Lua Nova [online], n. 36, p. 55-65, 1995. ISSN 0102-6445.

ELY, L. C. O discurso da sustentabilidade nas redes sociais: uma análise das interações no Facebook durante a Rio+20. 2013. 125f. Dissertação (Mestrado em Comunicação Social) - Pontifícia Universidade Católica do Rio Grande do Sul, Porto Alegre, 2013.

EM DISCUSSÃO. Rio+5 só reitera compromissos. Ano 3 - No 11 junho de 2012. Disponível em: <http://www.senado.gov.br/noticias/Jornal/ emdiscussao/rio20/a-rio20/forum-rio5-evento-da-onu-para-avaliacao-deresultados-da-conferencia-rio-92-sobre-o-desenvolvimento-sustentavel.aspx $>$. Acesso em: 5 out. 2017.

ESTEVA, G. Development. In: The Development Dictionary a guide to knowledge as power edited by Wolfgang Sachs, 2010.

FORUM BRASILEIRO DE ONGS E MOVIMENTOS SOCIAIS PARA O MEIO AMBIENTE - FBOMS. Brasil século XXI: os caminhos da sustentabilidade cinco anos depois da Rio- 92. LEROY, J. P.; MAIA, K. D.; GUIMARÃES, R. P. (Org.). Rio de Janeiro, FASE, 1997.

FRANCO, A. Pobreza e desenvolvimento local. Brasília: AED, 2002. 
GALVÃO, J. W. e S.; NASCIMENTO, D. M. A agenda ambiental nos planos de governo dos candidatos a prefeito das capitais da Amazônia legal nas eleições de 2012. In: BAHIA, M. C.; NASCIMENTO, D. M. (Org.). Estado, sistemas produtivos e populações tradicionais. Belém: NAEA, 2014, p. 18-38.

GIDDENS, A.; SUTTON, P. W. Conceitos essenciais de sociologia. 1. ed. São Paulo: Editora Unesp, 2016

GRANDELLE, R. Preocupação da sociedade com planeta leva empresas a investirem projetos sustentáveis. 05.06.2014. Disponível em: <https:// oglobo.globo.com/sociedade/sustentabilidade/preocupacao-da-sociedade-complaneta-leva-empresas-investir-em-projetos-sustentaveis-12723656>. Acesso em: 31 out. 2017.

GREEN, J. F. Rethinking private authority: agents and entrepreneurs in global environmental governance. Princeton University Press, 2014.

GUIMARÃES, R. P.; FONTOURA, Y. S. dos R. da. Rio+20 ou Rio-20?: crônica de um fracasso anunciado. Ambient. soc. [online]. 2012, v. 15, n.3, p.19-39. ISSN 1809-4422. http://dx.doi.org/10.1590/S1414-753X2012000300003.

HELD, D.; MCGREW,A; GOLDBLAT'T,D;PERRATON,J. Transformaciones globales: política, economía y cultura. México: Oxford University Press, 2002.

HURRELL, A.; KINGSBURY, B. (Ed.).The international politics of the environment. Oxford, Clarendon Press, 1992.

JANG, J.; MCSPARREN, J.; RASHCHUPKINA, Y. Global governance: present and future. Palgrave Communications 2, Article number: 15045. doi:10.1057/ palcomms.2015.45. 2016.

KALDOR, M. The idea of global civil society. International Affairs, 79(3), p. 583-593, maio 2003.

KAVALSKI, E. “Complexifying IR: Disturbing the "Deep Newtonian Slumber". In: KAVALSKI, E. (Ed.). World Politics at the Edge of Chaos: Reflections on Complexity and Global Life, Nova Iorque: State University of New York Press, 2016. p. 253-275.

KEOHANE, R.; NYE, J. S. Power and interdependence: world politics in transition. 3. ed. New York: Longman, 1977.

KRASNER, S. Causas Estruturais e Consequências dos Regimes Internacionais: regimes como variáveis intervenientes. Revista de Sociologia Política, Curitiba, v. 20, n.42, p. 93-110, 2012. 
LAGO, A. C. Estocolmo, Rio, Joanesburgo Brasil e as três conferências ambientais das Nações Unidas. Brasília, FUNAG, 2006.

LAMPREIA, L. F. A Rio + 20 foi um fracasso? 2012. Disponível em: < http:/ / blogs.oglobo.globo.com/lampreia/post/a-rio-20-foi-um-fracasso- 452290. html>. Acesso em: 20 jun. 2017.

LE PRESTRE, P. Ecopolítica internacional. São Paulo: Senac, 2000.

Global politics revisited. Towards a Complex Governance of Global Environmental Problems. Routledge, 2017.

LIPOVETSKY, G.; SERROY, J. A cultura-mundo, respostas a uma sociedade desorientada. São Paulo: Companhia das Letras, 2011.

LORENZETTT, M. A Rio+10 e os Governos Locais. Relatório Especial. Câmara dos Deputados, 2002.

LUHMANN, N. The reality of the mass media. Stanford, CA: Stanford University Press, 2000.

MARKET RESEARCH BLOG. Megatrend: Ethical Living is Pushing Companies to Become Socially Conscious. 2017. Não paginado. Disponível em: <https:// blog.euromonitor.com/megatrend-ethical-living/>. Acesso em: 31 out. 2017.

MARQUES, F. P. J. A. Debates políticos na internet: a perspectiva da conversação civil. Opinião Pública, Campinas-SP, v. 12, n. 1, p. 164-187, abr./maio, 2006.

MATURANA, H. R.; VARELA GARCIA, F. J. De máquinas e seres vivos: autopoiese; a organização do vivo. Porto Alegre: Artes Médicas, 1997.

NYE, J. S. Cooperação e conflito nas relações internacionais: uma leitura essencial para entender as principais questões da política mundial. São Paulo: Gente; 2009.

NOBEL FOUNDATION. Disponível em: < https://www.nobelprize.org>. Acesso em: 05 out. 2017.

OLIVEIRA, P. R. N. de; REIS, P. C. As estratégias de comunicação da marca rio em eventos de alta visibilidade: o caso da RIO+20. Revista Organicom ORGANICOM, v 10, n. 19, p. 231-248, 2. sem. 2013.

ONU - Organização das Nações Unidas. Além da Rio+20: Avançando rumo a um futuro sustentável. Rio de Janeiro, 2012b. Disponível em: <http://www. onu.org.br/rio20/alem-da-rio20-avancando-rumo-aum-futuro-sustentavel/>. Acesso em: 12 jul. 2017. 
A/RES/64/236.2010. Disponível em: <http://hotsite.mma.gov. $\mathrm{br} /$ rio20/wpcontent/uploads / Resolu\%C3\%A7\%C3\%A3o-64-236-daAssembl\%C3\%A9ia-Geral-da-ONUtraduzida.pdf>. Acesso em: 12 jul. 2017.

Declaração de Estocolmo. 1972. Disponível em: <http://www.onu. org.br/rio20/img/2012/01/estocolmo1972.pdf>. Acesso em: 10 jul. 2017.

Declaração de Joanesburgo sobre Desenvolvimento Sustentável. Joanesburgo. 2002. Disponível em: <http://www.onu.org.br/rio20/ img/2012/07/unced2002.pdf>. Acesso em: 09 jul. 2017.

Eco-92. Rio de Janeiro, 1992. Disponível em: <http://www.un.org/ geninfo/bp/enviro.html>. Acesso em: 09 jul. 2017.

Rio+20: como chegamos até aqui. 2012a. Disponível em: <http:// www.rio20.gov.br/sobre_a_rio_mais_20/rio-20-como-chegamos-ate-aqui/at_ download/rio-20-como-chegamos-ate-aqui.pdf>. Acesso em: 07 out. 2017.

Sobre a Rio+20. 2012c. Disponível em: <http://www.rio20.gov.br/ sobre_a_rio_mais_20.html $>$. Acesso em: 21 ago. 2017.

United Nations Convention on the Law of the Sea. 1982. Disponível em: <http://www.un.org/depts/los/convention_agreements/convention_ overview_convention.htm>. Acesso em: 05 out. 2017.

United Nations Conference to Negotiate a Legally Binding Instrument to Prohibit Nuclear Weapons, Leading Towards their Total Elimination. 2017. Disponível em: <https://www.un.org/disarmament/tpnw/ index.html>. Acesso em: 07 out. 2017.

ORSINI, A.; MORIN, J. F.; YOUNG, O. Regime complexes: A buzz, a boom, or a boost for global governance? Global governance, v. 19, 1, p. 27-39, 2014. Disponível em: <http://journals.rienner.com/doi/abs/10.5555/1075-284619.1.27>. Acesso em: 07 out. 2017.

OXFORD UNIVERSITY PRESS. Aplicativo dictionnary da Apple. 2017

ROSENAU, J.; CZEMPIEL, E. O. Governanças em governo. Ordem e transformação na política mundial. Brasília: UnB, 2000.

RUGGIE, J. Multilateralism: The anatomy of an institution. International Organization, 46(3), 561-598, 1982. doi:10.1017/S0020818300027831 1990

SABBAGH, M. I. I.; REIS, C. Desenvolvimento sustentável na imprensa: Cobertura da Rio +20 pelo Jornal de Santa Catarina. Intercom - Sociedade Brasileira de Estudos Interdisciplinares da Comunicação. Palhoça-SC. 2014. 
SEN, A. Desenvolvimento como liberdade. São Paulo: Companhia das Letras, 2010.

VEIGA, E. Para entender o desenvolvimento sustentável. São Paulo: Editora 34, 2015.

VIOLA, E.; FRANCHINI, M. Os limiares planetários, a Rio+20 e o papel do Brasil. Cad. EBAPE.BR, Rio de Janeiro, v. 10, n. 3, artigo 1, Set. 2012. Disponível em: <http://bibliotecadigital.fgv.br/ojs/index.php/cadernosebape/article/ view/5475>. Acesso em: 10 jul. 2017.

2018.

Brazil and climate change, Beyond the Amazon, Routledge, 
